University of Nebraska - Lincoln

DigitalCommons@University of Nebraska - Lincoln

\title{
Radiation-induced decomposition of the metal-organic molecule Bis(4-cyano-2,2,6,6-tetramethyl-3,5-heptanedionato)copper(II)
}

\author{
David Wisbey \\ University of Nebraska-Lincoln \\ Ning Wu \\ University of Nebraska-Lincoln \\ Yaroslav B. Losovyj \\ Louisiana State University at Baton Rouge, ylozovyy@indiana.edu \\ Ihor Ketsman \\ University of Nebraska-Lincoln, iketsman2@unlnotes.unl.edu
}

A. N. Caruso

University of Missouri - Kansas City, carusoan@umkc.edu

See next page for additional authors

Follow this and additional works at: https://digitalcommons.unl.edu/physicsdowben

Part of the Physics Commons

Wisbey, David; Wu, Ning; Losovyj, Yaroslav B.; Ketsman, Ihor; Caruso, A. N.; Feng, Danqin; Belot, John; Vescovo, Elio; and Dowben, Peter A., "Radiation-induced decomposition of the metal-organic molecule Bis(4-cyano-2,2,6,6-tetramethyl-3,5-heptanedionato)copper(II)" (2009). Peter Dowben Publications. 231. https://digitalcommons.unl.edu/physicsdowben/231

This Article is brought to you for free and open access by the Research Papers in Physics and Astronomy at DigitalCommons@University of Nebraska - Lincoln. It has been accepted for inclusion in Peter Dowben Publications by an authorized administrator of DigitalCommons@University of Nebraska - Lincoln. 


\section{Authors}

David Wisbey, Ning Wu, Yaroslav B. Losovyj, Ihor Ketsman, A. N. Caruso, Danqin Feng, John Belot, Elio Vescovo, and Peter A. Dowben 


\title{
Radiation-induced decomposition of the metal-organic molecule Bis(4-cyano-2,2,6,6-tetramethyl-3,5-heptanedionato)copper(II)
}

\author{
David Wisbey ${ }^{\mathrm{a}}$, Ning $\mathrm{Wu}^{\mathrm{a}}{ }^{\mathrm{a}}$, Yaroslav Losovyj ${ }^{\mathrm{b}}$, Ihor Ketsman ${ }^{\mathrm{a}}$, A.N. Caruso ${ }^{\mathrm{c}}$, Danqin Feng ${ }^{\mathrm{a}}$, \\ John Belot $^{\mathrm{d}}$, Elio Vescovo ${ }^{\mathrm{e}}$, Peter A. Dowben ${ }^{\mathrm{a}, *}$ \\ ${ }^{a}$ Department of Physics and Astronomy and the Nebraska Center for Materials and Nanoscience, 116 Brace Lab, University of Nebraska-Lincoln, Lincoln, NE 68588-0111, USA \\ ${ }^{\mathrm{b}}$ The J. Bennett Johnston Sr. Center for Advanced Microstructures and Devices, 6980 Jefferson Highway, Baton Rouge, LA 70806, USA \\ ${ }^{\mathrm{c}}$ Department of Physics, 257 Flarsheim Hall, University of Missouri - Kansas City, 5110 Rockhill Road, Kansas City KS 64110, USA \\ ${ }^{\mathrm{d}}$ Department of Chemistry and the Nebraska Center for Materials and Nanoscience, University of Nebraska, Lincoln, NE 68588-0304, USA \\ ${ }^{\mathrm{e}}$ Brookhaven National Laboratory, National Synchrotron Light Source, Upton, NY, 11973, USA
}

\section{A R T I C L E I N F O}

\section{Article history}

Received 15 August 2008

Received in revised form 16 September 2008

Accepted 30 September 2008

Available online 21 October 2008

PACS:

61.80.-X

33.80.Eh

82.30.Lp

79.60-i

Keywords:

Molecular magnets

Decomposition of organic compounds

Ultraviolet photoemission spectroscopy

\section{A B S T R A C T}

The effects of vacuum ultraviolet radiation on the adsorbed copper center molecule bis(4-cyano-2,2,6,6tetramethyl-3,5-heptanedionato)copper(II) (or $\left.\mathrm{Cu}(\mathrm{CNdpm})_{2}\right),\left(\mathrm{C}_{24} \mathrm{H}_{36} \mathrm{~N}_{2} \mathrm{O}_{4} \mathrm{Cu}, \mathrm{Cu}\right.$ (II)) was studied by photoemission spectroscopy. Changes in the ultraviolet photoemission spectra (UPS) of $\mathrm{Cu}(\mathrm{CNdpm})_{2}$, adsorbed on $\mathrm{Co}\left(\begin{array}{lll}1 & 1 & 1\end{array}\right)$, indicate that the ultraviolet radiation leads to decomposition of $\mathrm{Cu}(\mathrm{CNdpm})_{2}$ and this decomposition is initially dominated by loss of peripheral hydrogen.

(c) 2008 Elsevier B.V. All rights reserved.

\section{Introduction}

Metal organic molecules are very promising because it is possible to customize their electronic properties by changing metal centers or functional groups. Modification of a layer of large organometallic and metal-organic molecules, by way of radiation exposure, is not only very possible, but common also. For example, the decomposition of a number of metallocenes, as a result of ultraviolet radiation has been investigated including nickelocene [1], cobaltocene [2] and ferrocene [3,4]. Photochemical decomposition of cobalt phthalocyanine (CoPc) [5] and tris-(8-hydroxy quinoline aluminum $\left(\mathrm{Alq}_{3}\right)$ [6] has also been investigated, among many other species.

\footnotetext{
* Corresponding author at: Department of Physics and Astronomy and the Nebraska Center for Materials and Nanoscience, 116 Brace Lab, P.O. Box 880111, University of Nebraska-Lincoln, Lincoln, NE 68588-0111, USA. Tel.: +402 472 9838; fax: +404 4722879 .

E-mail address: pdowben@unl.edu (P.A. Dowben).
}

Such photodecomposition can lead to some valuable modifications of the molecular adlayer. In the case of monomolecular insulator $\left[1,1^{\prime} ; 4^{\prime}, 1^{\prime \prime}\right.$-terphenyl]-4,4' -dimethanethiol films, irradiation-induced modifications lead to cross-linking of the terphenyldimethanethiol molecules within the film, which results in a quasi-polymeric material with improved dielectric properties [710]. While irradiation-induced modifications tend to lead to decomposition and desorption processes in aliphatic organic adlayers, cross-linking is the dominant effect in the aromatic ones, resulting in a quasi-polymerization of the monomolecular film [11-13]. Such polymer-like but ordered layers provide the possibility of using the organic self assembled monolayers as ultrathin insulating layers in electronic and spintronic devices [7-13].

Here, we investigate the irradiation-induced modification of adsorbed copper metal center molecule bis(4-cyano-2,2,6,6tetramethyl-3,5-heptanedionato)copper(II) (or $\mathrm{Cu}(\mathrm{CNdpm})_{2}$ ). This is a copper metal center molecule, schematically illustrated in the inset to Fig. 1, where N1' and N2" represent the nitrogen atoms from the nearest neighbors. Like the metal 

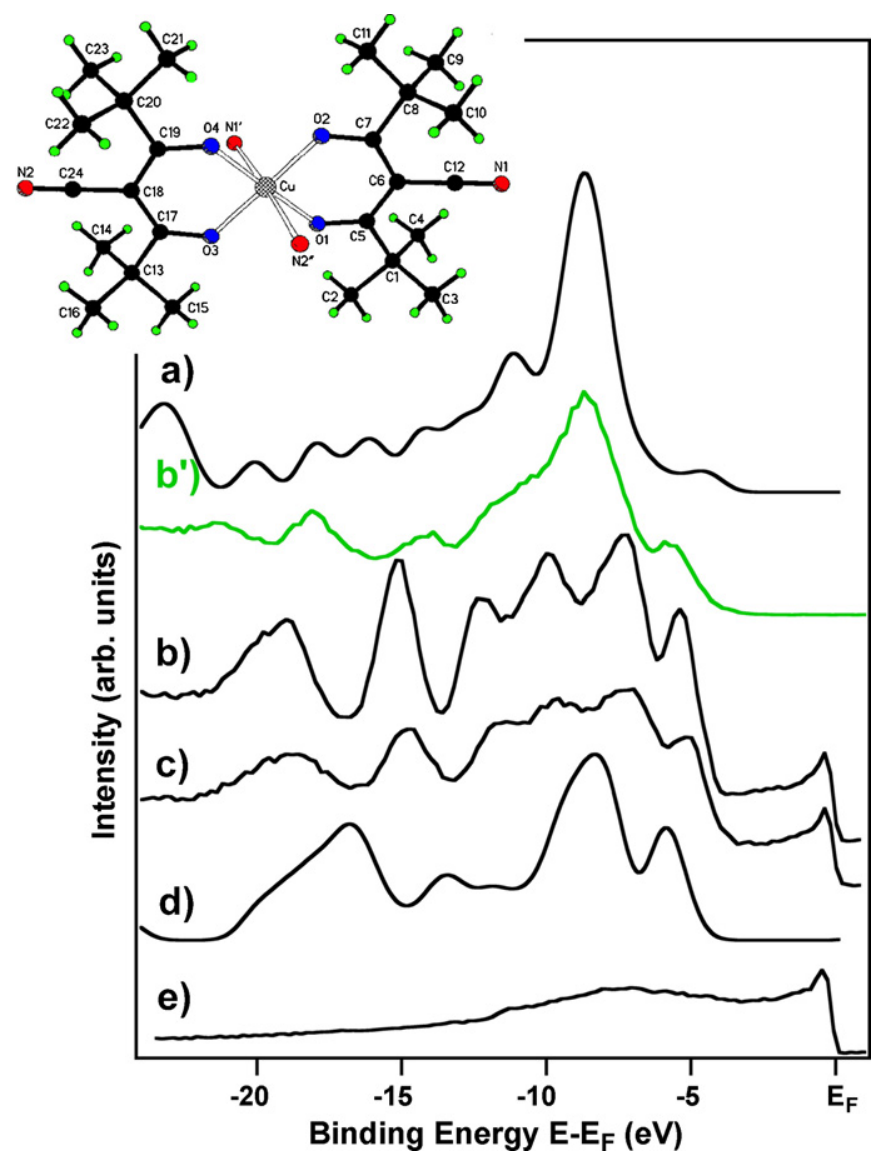

Fig. 1. The experimental photoemission spectra of adsorbed $\mathrm{Cu}(\mathrm{CNdpm})_{2}$, and the changes resulting from irradiation-induced modifications. Spectrum (a) shows a model density of states for the occupied molecular orbitals of $\mathrm{Cu}(\mathrm{CNdpm})_{2}$, with all the hydrogen atoms attached. Spectra $\left(b\right.$ and $\left.b^{\prime}\right)$ are of the pristine molecular thin films of $\mathrm{Cu}(\mathrm{CNdpm})_{2}$ on $\mathrm{Co}\left(\begin{array}{lll}1 & 1 & 1\end{array}\right)$ at $100 \mathrm{~K}$ or less, prior to any photo-degradation. The spectrum (b), taken at a photon energy of $49 \mathrm{eV}$, tends to emphasize the ligand contributions while $\left(b^{\prime}\right)$, taken at $79 \mathrm{eV}$ photon energy (of a 50 molecular monolayer thick film) tends to emphasize the molecular orbitals with copper weight. Decomposition of $\mathrm{Cu}(\mathrm{CNdpm})_{2}$ is evident in photoemission after exposure to roughly $1.2 \times 10^{17}$ photons $/ \mathrm{cm}^{2}$ of about $50 \mathrm{eV}$ photon energy (c), while (e) is after roughly an additional $10^{18}$ photons $/ \mathrm{cm}^{2}$ of about $50 \mathrm{eV}$ photon energy. For comparison, a model density of states for the occupied molecular orbitals of $\mathrm{Cu}(\mathrm{CNdpm})_{2}$, with all the peripheral hydrogen atoms removed is illustrated in (d). Spectra (b, c, and e) were taken at $49 \mathrm{eV}$ photon energy and at a substrate temperature of $40 \mathrm{~K}$. The inset shows the single-crystal structure of $\mathrm{Cu}(\mathrm{CNdpm})_{2}$ adapted from reference $[14,19]$.

phthalocyanines, $\mathrm{Cu}(\mathrm{CNdpm})_{2}$ has large ligands surrounding a metal core. Ultraviolet radiation enhanced decomposition of CoPc may possibly be a means for fabrication of nanostructured metal oxide films [5], and this might apply to $\mathrm{Cu}(\mathrm{CNdpm})_{2}$ as well. The photodecomposition of $\mathrm{Cu}(\mathrm{CNdpm})_{2}$, on the other hand, if restricted to the loss of peripheral hydrogens, could be used for enhancing the cross linking in the molecular film and fabrication of a copper atom containing polymer, without copper atom clustering.

\section{Experimental}

Synthesis of bis(4-cyano-2,2,6,6-tetramethyl-3,5-heptanedionato)copper(II) (or $\left.\mathrm{Cu}(\mathrm{CNdpm})_{2}\right),\left(\mathrm{C}_{24} \mathrm{H}_{36} \mathrm{~N}_{2} \mathrm{O}_{4} \mathrm{Cu}, \mathrm{Cu}\right.$ (II)) was described previously [14]. $\mathrm{Cu}(\mathrm{CNdpm})_{2}$ was adsorbed molecularly, from the vapor, onto the surface of epitaxial $\operatorname{Co}\left(\begin{array}{lll}1 & 1 & 1\end{array}\right)$. The $\mathrm{Cu}(\mathrm{CNdpm})_{2}$ molecules were deposited on $\mathrm{Co}\left(\begin{array}{lll}1 & 1 & 1\end{array}\right)$ at about $40 \mathrm{~K}$, diminishing the possibility of any thermal degradation.
The epitaxial Co(l $\left.\begin{array}{lll}1 & 1 & 1\end{array}\right)$ substrate films were grown prior to each experiment on $\mathrm{Cu}\left(\begin{array}{lll}1 & 1 & 1\end{array}\right)$ single crystals, to a cobalt thickness of $20 \AA$ or about 7 monolayers (ML), as described in prior work $[15,16]$. The clean $\mathrm{Cu}\left(\begin{array}{lll}1 & 1 & 1\end{array}\right)$ surfaces were prepared by repeated cycles of $\mathrm{Ar}+$ ion sputtering and annealing of a $\mathrm{Cu}$ single crystal, prior to Co deposition.

Ultraviolet photoemission spectra (ARPES) of the adsorbed molecular layers on $\mathrm{Co}\left(\begin{array}{lll}1 & 1 & 1\end{array}\right)$ were acquired at the U5UA undulator spherical grating monochromator (SGM) beamline at the National Synchrotron Light Source (NSLS) [17,18], as described elsewhere [15]. The ultrahigh vacuum photoemission end-station at the SGM beamline was equipped with a hemispherical electron energy analyzer (EA125, Omicron $\mathrm{GmbH}$ ) $[17,18]$. The analyzer had a $\pm 2^{\circ}$ angular resolution while the combined energy resolution of the analyzer and the light source was approximately $150 \mathrm{meV}$ or less. The photoemission spectra were taken at a $45^{\circ}$ light incidence angle, with the photoelectrons collected normal to the surface.

The irradiation-induced decomposition was the result of continual exposure to light from the undulator beam line at photon energies in the region of $49 \mathrm{eV}$, similar to the studies of nickelocene decomposition, as described in [1], carried out with vacuum ultraviolet radiation at $50 \mathrm{eV}$.

\section{Irradiation and photo-degradation of adsorbed $\mathrm{Cu}(\mathrm{CNdpm})_{2}$ on $\operatorname{Co}\left(\begin{array}{lll}1 & 1 & 1\end{array}\right)$}

$\mathrm{Cu}(\mathrm{CNdpm})_{2}$ is close to being a copper spin $1 / 2$ system [19] and adsorbs molecularly with a strong preferential molecular orientation [15]. As demonstrated in previous work [15,19], $\mathrm{Cu}(\mathrm{CNdpm})_{2}$ adsorbed onto the surface of $\operatorname{Co}\left(\begin{array}{lll}1 & 1 & 1\end{array}\right)$ provides photoemission spectra very similar to adsorption on $\mathrm{Cu}\left(\begin{array}{lll}1 & 1 & 1\end{array}\right)$, in spite of expected differences in substrate reactivity. For the thicker molecular films (50 molecular layers), the photoemission spectra taken at higher photon energies of $79 \mathrm{eV}$ (Fig. 1 $\mathrm{b}^{\prime}$ ) closely resemble expectation (Fig. 1a), obtained from semiempirical NDO-PM3 (neglect of differential diatomic overlap, parametric model number 3) model calculations based on Hartree-Fock formalism [20]. Although PM3 is a simplistic semiempirical calculation it is preferable here to density functional theory (DFT), which is notorious for underestimating the band gap sometimes by a factor 2 or more [21], particularly for molecular systems. DFT must be rescaled for comparison with experiment [22], particularly with final state spectroscopies like photoemission and inverse photoemission. To compare the model calculations with experiment (Fig. 1), we applied Gaussian envelopes of $1.2 \mathrm{eV}$ width to each calculated molecular orbital energy (Eigen value) to account for the solid state broadening in photoemission and then summed. The orbital energies for this model density of states calculations has been rigidly shifted in energy by $4.4 \mathrm{eV}$ and then compared to the photoemission data.

As described in [15], the spectrum taken at a photon energy of $49 \mathrm{eV}$ (Fig. 1b) tends to emphasize the ligand contributions, while that in Fig. $1 b^{\prime}$, taken at $79 \mathrm{eV}$ photon energy, tends to emphasize the molecular orbitals with copper weight. It is the latter that shows the better agreement with expectation.

To study possible ligand fragmentation as a result of irradiation, a sequence of photoemission spectra was taken with a photon energy of $49 \mathrm{eV}$. Fig. 2 illustrates the gradual change in the photoemission spectra of 7 molecular monolayers films of $\mathrm{Cu}(\mathrm{CNdpm})_{2}$ deposited on $\mathrm{Co}\left(\begin{array}{lll}1 & 1 & 1\end{array}\right)$, after exposure to radiation for increasing amounts of time, up to an exposure of roughly $10^{17}$ photons $/ \mathrm{cm}^{2}$ of about $50 \mathrm{eV}$ photon energy. The peak closest to the Fermi energy level in all the spectra in Fig. 2 originates from the Co $3 \mathrm{~d}$ bands of the underlying $\operatorname{Co}\left(\begin{array}{lll}1 & 1 & 1\end{array}\right)$ substrate. All the spectra were aligned with the substrate Fermi level. 


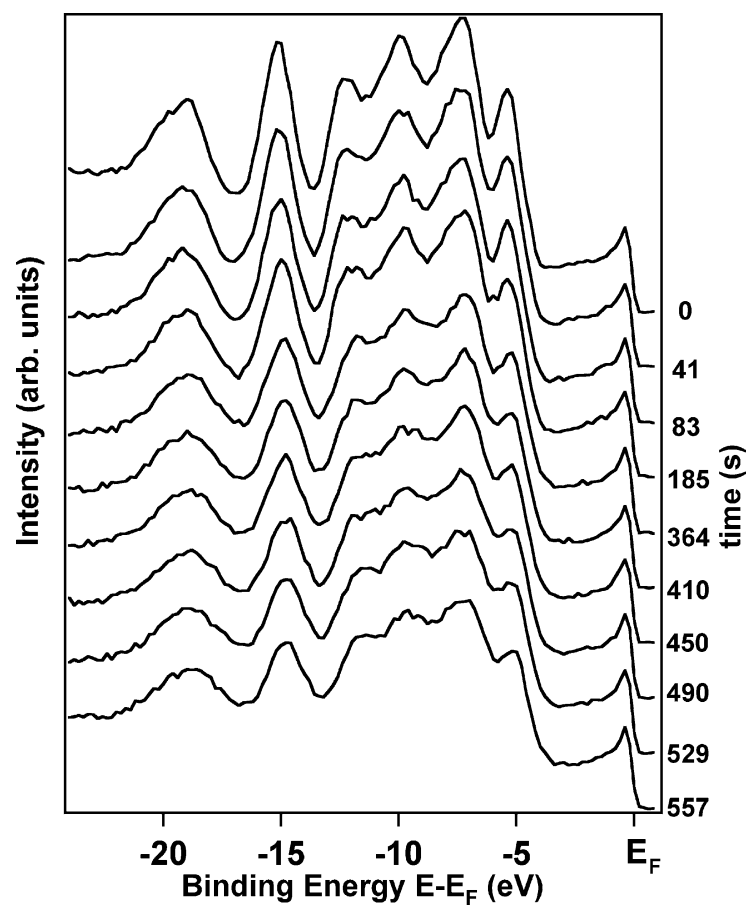

Fig. 2. The photoemission spectra of $\mathrm{Cu}(\mathrm{CNdpm})_{2}$ deposited on $\mathrm{Co}\left(\begin{array}{lll}1 & 1 & 1\end{array}\right)$ at about $40 \mathrm{~K}$, as a function of increasing exposure to radiation. The spectra were taken at a photon energy of $49 \mathrm{eV}$. The numbers on the right indicate exposure time to radiation at the beginning of each spectrum, with the last spectrum corresponding to an exposure of roughly $10^{17}$ photons $/ \mathrm{cm}^{2}$. All spectra were taken using $\mathrm{Cu}(\mathrm{CNdpm})_{2}$ molecular thin films $7 \mathrm{ML}$ thick on $\mathrm{Co}\left(\begin{array}{lll}1 & 1\end{array}\right)$ at substrate temperatures of $\sim 40 \mathrm{~K}$.

The photoemission spectra (Fig. 2) do not provide indications of ligand decomposition occurring with photo-irradiation in the vacuum ultraviolet. The first three peaks attributable to the $\mathrm{Cu}(\mathrm{CNdpm})_{2}$, in the photoemission spectra of Fig. 2, occur at binding energies of $5 \mathrm{eV}$ and greater. After about 500-600 s of exposure to low intensity UV radiation corresponding to exposure of roughly $10^{17}$ photons $/ \mathrm{cm}^{2}$ or less, the main peaks between $5 \mathrm{eV}$ and $12 \mathrm{eV}$ binding energy, Fig. 1(c), are much less distinct when compared with the pristine film (Fig. 1(b)). This is summarized in Fig. 3, where a significant increase in the full width, at half maximum, of the photoemission features attributable to molecular $\mathrm{Cu}(\mathrm{CNdpm})_{2}$ deposited on $\mathrm{Co}\left(\begin{array}{llll}1 & 1 & 1\end{array}\right)$ is indicated. This significant increase in photoemission peak width is less profound for the feature resulting from the highest lying occupied molecular orbitals, and in fact is not observed for that feature (feature ' $A$ ' in Fig. 3). The feature derived from the highest lying occupied molecular orbitals exhibits a dramatic decrease in intensity above $500 \mathrm{~s}$ of exposure to synchrotron radiation at a photon energy of about $50 \mathrm{eV}$. In fact, as indicated in Fig. 4, there is a shift of intensity from the highest lying occupied molecular orbitals (feature ' $A$ ', as labeled in the inset to Fig. 3 ) to high binding energies features (feature ' $\mathrm{B}$ ', as labeled in the inset to Fig. 3). Thus the photoemission feature resulting from the highest lying occupied molecular orbitals, differs from the other $\mathrm{Cu}(\mathrm{CNdpm})_{2}$ molecular orbital derived photoemission features.

After exposure to low intensity UV radiation corresponding to exposure of roughly $10^{17}$ photons $/ \mathrm{cm}^{2}$, the main photoemission features, attributable to the $\mathrm{Cu}(\mathrm{CNdpm})_{2}$ molecular orbitals, are still present (Fig. 2). The small decreases in the binding energies of some of the molecular orbital derived photoemission features, leading to shifts towards the Fermi level, are consistent with changes caused by loss of hydrogen atoms. With modest amounts of UV radiation (roughly $10^{17}$ photons $/ \mathrm{cm}^{2}$ ) these photoemission features of molecular origin decrease in binding energy, shifting by about $0.2 \pm 0.1 \mathrm{eV}$ towards the Fermi level, and become much less distinct. Also, the photoemission peak at $15 \mathrm{eV}$ binding energy, nearly solely of ligand origin, is seen to shift by around $0.4 \pm 0.1 \mathrm{eV}$ towards the Fermi level. The photoemission peak around $18 \mathrm{eV}$ does not shift in energy position with exposure to very modest radiation (Fig. 2).

While ligand fragmentation probably does not occur until exposure to low intensity UV radiation corresponding to exposure of roughly $10^{17}$ photons $/ \mathrm{cm}^{2}$ (at about $50 \mathrm{eV}$ photon energy), hydrogen loss may occur with very little radiation exposure as indicated by the loss in peak intensities, in Fig. 4. Intensity loss in the photoemission features due to the $\mathrm{Cu}(\mathrm{CNdpm})_{2}$ molecular orbitals at less than $50 \mathrm{~s}$ exposure is accompanied by an enhancement of the substrate Co $3 d$ bands nearest to the Fermi level. These changes in the spectra could well be the result of simple photo-induced desorption. Generally, except possibly at the very initial exposures to radiation, since enhancement of the substrate Co $3 \mathrm{~d}$ bands nearest to the Fermi level, with radiation exposure, is not apparent in Fig. 2, the irradiation modification is not a result of significant molecular desorption, as may be the case with similar experiments of nickelocene adsorbed on $\operatorname{Ag}\left(\begin{array}{lll}1 & 0 & 0\end{array}\right)$ [1].

Okudaira et al. [23] also observed small shifts towards the Fermi level with irradiation-induced decomposition of poly(methyl methacrylate), and as in the case of adsorbed $\left[1,1^{\prime} ; 4^{\prime}, 1^{\prime \prime}-\right.$ terphenyl]-4,4"-dimethanethiol films [7-10], some dehydrogenation is implicated. These binding energy shifts of the photoemission features could indicate a formation of a smaller band gap between the highest occupied (HOMO) and lowest unoccupied (LUMO) molecular orbitals. This would be consistent with a loss of $\mathrm{H}$ atoms $[10,24,25]$. In practice, inverse photoemission studies

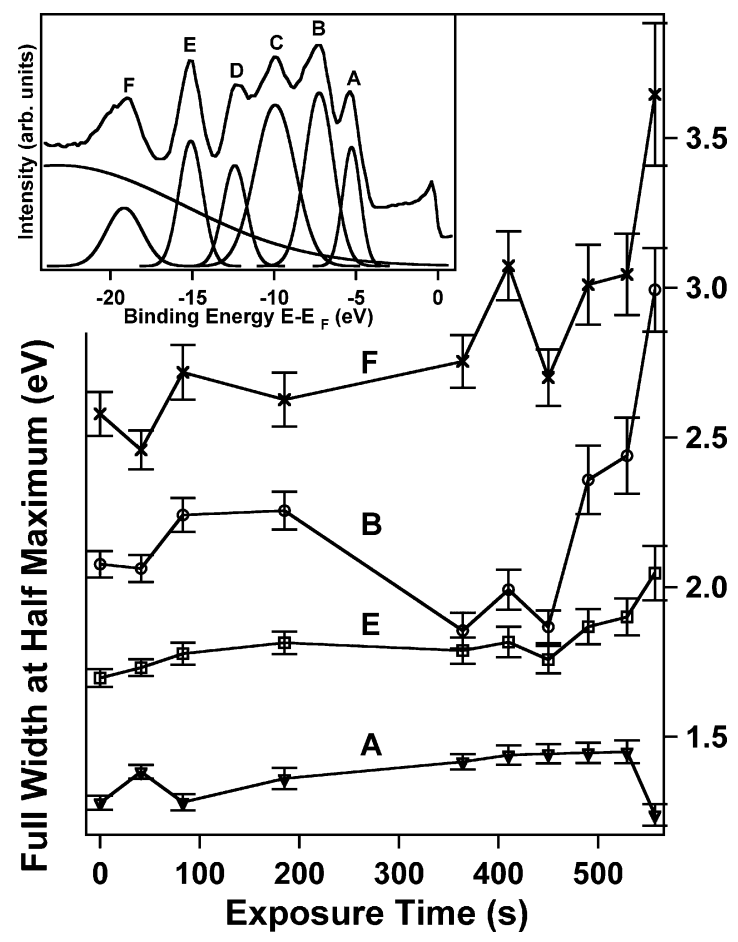

Fig. 3. The full width at half maximum of select photoemission features attributable to the molecular $\mathrm{Cu}(\mathrm{CNdpm})_{2}$, as a function of increasing exposure to radiation. The data were obtained from spectra taken at a photon energy of $49 \mathrm{eV}$, as in Fig. 2. The assignment of the various curves follows the assignment of the features for molecular $\mathrm{Cu}(\mathrm{CNdpm})_{2}$, as indicated in the spectrum in the inset at the upper left Data here are for $\mathrm{Cu}(\mathrm{CNdpm})_{2}$ molecular thin films $7 \mathrm{ML}$ thick on $\mathrm{Co}\left(\begin{array}{lll}1 & 1 & 1\end{array}\right)$ at substrate temperatures of $\sim 40 \mathrm{~K}$. 


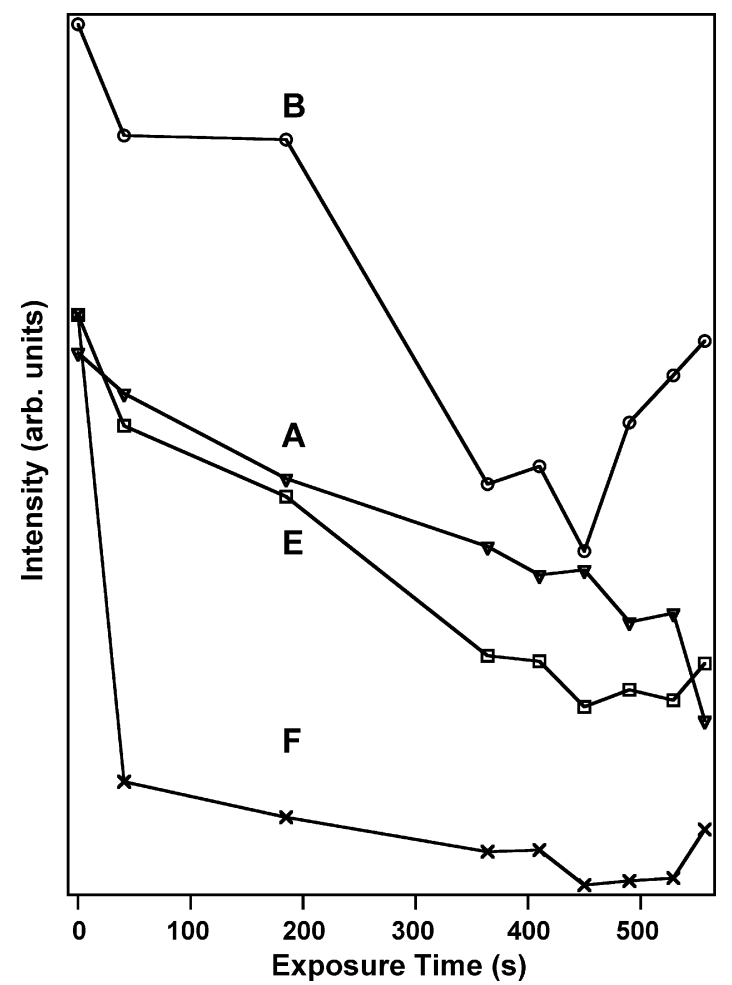

Fig. 4. The integral peak intensities for select photoemission features attributable to the molecular $\mathrm{Cu}(\mathrm{CNdpm})_{2}$, as a function of increasing exposure to radiation. The data were obtained from spectra taken at a photon energy of $49 \mathrm{eV}$, as in Fig. 2. The assignment of the various curves follows the assignment of the features for molecular $\mathrm{Cu}(\mathrm{CNdpm})_{2}$, as indicated in the spectrum in the inset at the upper left to Fig. 3. Data here are for $\mathrm{Cu}(\mathrm{CNdpm})_{2}$ molecular thin films $7 \mathrm{ML}$ thick on $\mathrm{Co}\left(\begin{array}{lll}1 & 1 & 1\end{array}\right)$ at substrate temperatures of $\sim 40 \mathrm{~K}$.

would be necessary to determine if the HOMO-LUMO gap decreased.

To support the contention that initially dehydrogenation dominates irradiation-induced fragmentation, a number of model calculations were undertaken. Fig. 1(a) shows the $\mathrm{Cu}(\mathrm{CNdpm})_{2}$ molecular orbital density of states with all the hydrogen atoms attached. While our model calculations do not take into account the change in the photoemission cross sections with photon energy, nor any matrix element effects, the shifts in binding energies seen in photoemission resemble the changes expected for dehydrogenation (Fig. 1d).

While the decomposition and desorption processes prevail in aliphatic self-assembled monolayers, Caruso et al. [24] pointed out that for the closo-carborane, the main photoemission features are preserved with exposure to synchrotron white light. As is the case here, this indicates that a heterogeneous mixture of carbon species is not formed. Rather, the structure of the molecule is preserved while decomposition is dominated by the loss of hydrogen [26,27]. The absence of shifts in the photoemission feature at around $18 \mathrm{eV}$, while the ligand derived molecular orbital features do shift towards smaller binding energies, with exposure to radiation, also supports the postulate that initial irradiation leads to hydrogen loss for $\mathrm{Cu}(\mathrm{CNdpm})_{2}$ deposited on $\mathrm{Co}\left(\begin{array}{lll}1 & 1 & 1\end{array}\right)$ at about $40 \mathrm{~K}$. While irradiation-induced fragmentation of the ligand -C-C- backbone cannot be excluded by either the data or model calculations, and remains quite likely, this does not appear to be the dominant fragmentation process with initial irradiation.

As with the case of adsorbed $\left[1,1^{\prime} ; 4^{\prime}, 1^{\prime \prime}\right.$-terphenyl $]-4,4^{\prime \prime}$ dimethanethiol films [7-10], and other molecular adlayers, extensive irradiation leads to fragmentation beyond simple

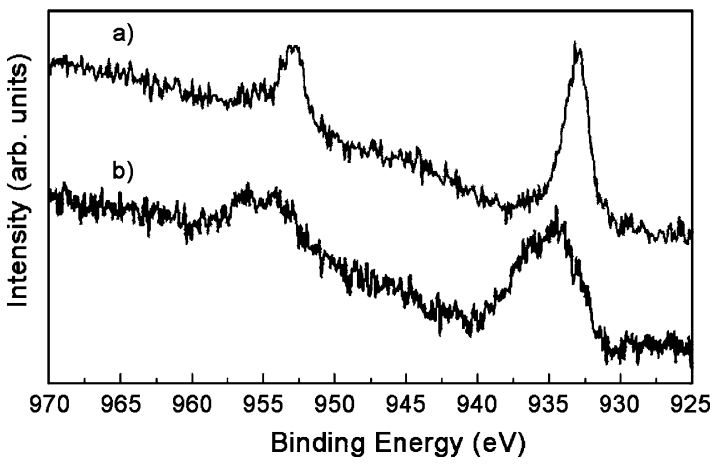

Fig. 5. The $\mathrm{Cu} 2 \mathrm{p}_{1 / 2}$ and $2 \mathrm{p}_{3 / 2} \mathrm{X}$-ray photoelectron spectra for $\mathrm{Cu}(\mathrm{CNdpm})_{2}$ following deposition (a), and irradiation (b). The decomposition of $\mathrm{Cu}(\mathrm{CNdpm})_{2}$, due to irradiation leads to a species with greater binding energy (b). All binding energies are referenced to the Fermi level.

dehydrogenation of peripheral hydrogens. As seen in Fig. 1d, high irradiation levels lead to the loss of all of the molecular orbital features, and as noted elsewhere [19], to a large shift in the core level binding energies. The XPS $\mathrm{Cu} 2 \mathrm{p}$ photoemission for adsorbed $\mathrm{Cu}(\mathrm{CNdpm})_{2}$ is shown in Fig. 5 . The $\mathrm{Cu} 2 \mathrm{p}_{3 / 2}$ binding energy for $\mathrm{Cu}(\mathrm{CNdpm})_{2}(932.8 \pm 0.2 \mathrm{eV})$, is a slightly higher binding energy than for copper metal (932.3-932.5 eV [28-30] for the $\mathrm{Cu}_{2} \mathrm{p}_{3 / 2}$ ) but less than the value expected for copper in $\mathrm{CuO}$ (933.4 eV [28] to 933.6 eV [29] to $933.7 \mathrm{eV}$ [30-32]). Thus our values for the $\mathrm{Cu} 2 \mathrm{p}_{3 / 2}$ binding energy for $\mathrm{Cu}(\mathrm{CNdpm})_{2}(932.8 \pm 0.2 \mathrm{eV})$ are somewhat smaller than expected, even compared to a similar copper compartmental complex 6,11-dimethyl-7, 10 diazahexadeca-5, 11-diene2,4,13,15-tetraene [ $\mathrm{Cu}\left(\mathrm{H}_{2}\right.$ daaen $\left.)\right]$ (934.1 eV [33]), which should have a similar (or even smaller) charge transfer from the $\mathrm{Cu}$ metal center. By way of comparison, we find that the $\mathrm{Cu} 2 \mathrm{p}_{3 / 2}$ core level binding energies for $\mathrm{Cu}(\mathrm{CNdpm})_{2}$ exhibit increase to $935 \mathrm{eV}$ or more after molecular decomposition initiated by either photon or electron irradiation. The greater binding energies are more in line with values indicative of a copper oxide insulator, with a weakly screened final state.

\section{Summary}

In conclusion, we have shown that $\mathrm{Cu}(\mathrm{CNdpm})_{2}$ is affected by radiation. With ultraviolet radiation, the initial decomposition appears to lead to the loss of peripheral hydrogen from the molecule, but with much of the molecular backbone preserved. As seen in the photoemission spectra of adsorbed $\mathrm{Cu}(\mathrm{CNdpm})_{2}$, irradiation leads to binding energy shifts of the occupied molecular orbitals towards the Fermi level. If cross-linking of this or similar species could be demonstrated, then a route to the formation of a widely dispersed copper metallized polymer may be possible. For large amounts of radiation, in the region of $10^{18}$ photons $/ \mathrm{cm}^{2}$, the loss of the features associated with adsorbed $\mathrm{Cu}(\mathrm{CNdpm})_{2}$ is evident. With such extreme photodecomposition it is hard to see how the decomposition of $\mathrm{Cu}(\mathrm{CNdpm})_{2}$ will differ substantively from photochemical decomposition of cobalt phthalocyanine $(\mathrm{CoPc})$ reported previously [5].

\section{Acknowledgments}

This research was supported by the National Science Foundation through grant number CHE-0415421 and CHE-0650453. The Center for Advanced Microstructures and Devices (CAMD) is supported by the Louisiana Board of Regents. The NSLS is supported by the United States Department of Energy, Office of Science, Office of Basic Energy Sciences, under contract No: 
DE-AC02-76CH00016. We thank Neil M. Boag for synthesizing samples of $\mathrm{Cu}(\mathrm{CNdpm})_{2}$, the technical assistance of Camelia Borca and acknowledge a number of helpful discussions with Neil Boag.

\section{References}

[1] D. Welipitiya, C. Waldfried, C.N. Borca, P.A. Dowben, N.M. Boag, H. Jiang, I. Gobulukogula, B. Robertson, Surf. Sci. 418 (1998) 466

[2] L. Carlson, D. Lagraffe, S. Balaz, A. Ignatov, Y.B. Losovyj, J. Choi, P.A. Dowben, J.I. Brand, Appl. Phys. A 89 (2007) 195.

[3] D. Welipitiya, A. Green, J.P. Woods, P.A. Dowben, B.W. Robertson, D. Byun, J. Zhang, J. Appl. Phys. 79 (1996) 8730.

[4] P.A. Dowben, C. Waldfried, T. Komesu, D. Welipitiya, T. McAvoy, E. Vescovo, Chem. Phys. Lett. 283 (1998) 44

[5] N. Ohta, M. Gomi, Jpn. J. Appl. Phys. 39 (2000) 4195.

[6] N. Koch, D. Pop, R.L. Weber, N. Böwering, B. Winter, M. Wick, G. Leising, I.V. Hertel, W. Braun, Thin Solid Films 391 (2001) 81.

[7] Y. Tai, A. Shaporenko, H. Noda, M. Grunze, M. Zharnikov, Adv. Mater. 17 (2005) 1745.

[8] Y. Tai, A. Shaporenko, M. Grunze, M. Zharnikov, J. Phys. Chem. B 109 (2005) 19411.

[9] H. Noda, Y. Tai, A. Shaporenko, M. Grunze, M. Zharnikov, J. Phys. Chem. B 109 (2005) 22371.

[10] D. Feng, Y. Losovyj, Y. Tai, M. Zharnikov, P. Dowben, J. Mater. Chem. 16 (2006) 4343.

[11] M. Zharnikov, M. Grunze, J. Vac. Sci. Technol. B 20 (2002) 1793.

[12] W. Geyer, V. Stadler, W. Eck, M. Zharnikov, A. Gölzhäuser, M. Grunze, Appl. Phys. Lett. 75 (1999) 2401.

[13] W. Eck, V. Stadler, W. Geyer, M. Zharnikov, A. Gölzhäuser, M. Grunze, Adv. Mater. $12(2000) 805$.

[14] C.M. Silvernail, G. Yap, R.D. Sommer, A.L. Rheingold, V.W. Day, J.A. Belot, Polyhedron 20 (2001) 3113.
[15] D. Wisbey, N. Wu, D. Feng, A.N. Caruso, J. Belot, Y. Losovyj, E. Vescovo, P.A. Dowben, J. Phys. Chem. C 112 (2008) 13656.

[16] Q. Chen, M. Onellion, A. Wall, P.A. Dowben, J. Phys. Cond. Matter. 4 (1992) 7985.

[17] E. Vescovo, H.-J. Kim, Q.-Y. Dong, G. Nintzel, D. Carlson, S. Hulbert, N.V. Smith, Synchrotron Radiat. News 12 (1999) 10.

[18] P.D. Johnson, N.B. Brooks, S.L. Hulbert, R. Klaffy, A. Clarke, B. Sinković, N.V. Smith, R. Celotta, M.H. Kelly, D.T. Pierce, M.R. Sheinfein, B.J. Waclawski, M.R. Howells, Rev. Sci. Instrum. 63 (1992) 1902.

[19] D. Wisbey, D. Feng, M.T. Bremer, C.N. Borca, A.N. Caruso, C.M. Silvernail, J. Bellot, E. Vescovo, L. Ranno, P.A. Dowben, J. Am. Chem. Soc. 129 (2007) 6249.

[20] J.J.P. Stewart, “PM3”, Encyclopedia of Computational Chemistry, Wiley, USA, 1998.

[21] I.N. Yakovkin, P.A. Dowben, Surf. Rev. Lett. 14 (2007) 481.

[22] A.M. Scheer, P.D. Burrow, J. Phys. Chem. B 110 (2006) 17751.

[23] K. Okudaira, S. Hasegawa, P.T. Sprunger, E. Morikawa, V. Saile, K. Seki, Y. Harada, N. Ueno, J. Appl. Phys. 83 (1998) 4292-4298.

[24] A.N. Caruso, R.B. Billa, S. Balaz, J.I. Brand, P.A. Dowben, J. Phys. : Condens. Matter 16 (2004) L139.

[25] P. Lunca-Popa, J.I. Brand, S. Balaz, L.G. Rosa, N.M. Boag, B. Mengjun, B.W. Robertson, P.A. Dowben, J. Phys. D: Appl. Phys. 38 (2005) 1248.

[26] Norman Riehs, Bachelorarbeit, "Photoionisation und Fragmentation von closoDicarbadodecaboranen und closo-Phosphacarbadodecaboranen mit Synchrotronstrahlung", Physikalische und Theoretische Chemie, Freie Universität Berlin, Takustr. 3, D-14195 Berlin, 2007.

[27] N.F. Riehs, H.-W. Jochims. E. Serdaroglu, E. Rühl, P.A. Dowben, BESSY Annual Report, (2007) 384-385.

[28] J. Moulder, W. Stickle, P. Sobol, K. Bomben, Handbook of X-Ray Photoelectron Spectroscopy, PerkinElmer Corporation, USA, 1992.

[29] D. Briggs, M.P. Seah, 2nd ed., Practical Aurface Analysis, 1, John Wiley \& Sons, USA, 1993.

[30] T.L. Barr, J. Phys. Chem. 82 (1978) 1801.

[31] T.L. Barr, J. Vac. Sci. Technol. A 9 (1991) 1793.

[32] G. Haemers, J.J. Verbist, S. Maroie, Appl. Surf. Sci. 17 (1984) 463.

[33] Q. Liu, H. Yu, X. Zhang, Z. Zhang, J. Mol. Struct. 478 (1999) 23. 